\title{
Business Model Based on the Sharing Economy: A Multi-Case Study Yanli Guo ${ }^{a}$, Jie Geng ${ }^{b}$, Jianbin Chen ${ }^{c}$ \\ Business College of Beijing Union University,Yanjingdongli,ChaoyangDistrict,Beijing,China aYanli.guo@buu.edu.cn, b13521306056@163.com, ' Jianbin.chen@buu.edu.cn
}

Keywords: Sharing Economy, Business Model, Business Model Canvas, Collaborative Consumption, Collaborative Production

\begin{abstract}
Sharing economy has become an important business model of modern service innovation. In recent years, many sharing economy enterprises have appeared in the fields of house renting, car rental, office space leasing and catering, etc., but it is not enough yet that research on the theory of sharing economy or the theoretical summary about the essential features and inherent rules of sharing economy innovation. This paper classifies the models of sharing economy and surveys the different types of cases to discuss the ingredients and characteristics of sharing economy based on business model canvas. The conclusion would help us to understand the essential connotation and characteristics of sharing economy.
\end{abstract}

\section{Introduction}

In 2015, it was estimated that the market size of share economy was about 1.956 trillion Yuan in China. In the next five years, the anticipated average annual growth rate is about $40 \%$, and market size will amount to more than 10\% of GDP by 2020 [1]. It is foreseeable that endless sharing economy based business models will emerge in the future. Currently widespread phenomenon is that almost all the companies say their business model is a sharing economic innovation. In order to win attentions from customers, they are blindly hyping the new conception, don't really understand the nature of the sharing economic business model, it is unfavorable to the development of service innovation. In this paper, a series of studies have been carried out to understand what is sharing economy and the models of sharing economy, and what kind of factors will be needed for the business model innovation based on the sharing economy model.

\section{The types of Sharing Economic Models}

\subsection{Rachel Botsman's theory}

Rachel Botsman[2] argues that there are three patterns of sharing economy: (1) Redistribution markets, such as second-hand markets. (2) Collaborative lifestyles. It maybe includes sharing of money, technology, time and space resources, such as shared workspaces. (3) Product service system. It is transferring of the right to use, such as vehicle rental website, and short-rental accommodation network [3].

\subsection{Weitzman's Classification}

Based on the research of Witzman [4][5][6][7][8], there are three categories of sharing economy from the view of share content: First, product service based on sharing and leasing. It refers to transferring of the usage rights of product, such as carpool. Second, product re-circulation based on the second-hand transferring, that's transferring of the ownership of product. Third, collaborative lifestyles based on shared assets and skill, that's sharing of intangible assets such as time, knowledge and skills.

\subsection{Classification from China National Information Centre}

In April, 2016, the sharing economy development report was released by research group of China National Information Centre. In this report, the sharing economy has been divided into six categories based on the different sharing object. There are product sharing, space sharing, knowledge and skill sharing, labor sharing, fund sharing and production capacity sharing. 
Based on above-mentioned classifications, in this paper, we summarize three models of the sharing economy as following: (1) Product or service sharing: based on transferring of the right to use on the premise that the ownership is unchanged, such as Didi and Uber. (2) Collaborative lifestyles: sharing of intangible resources such as time, knowledge and skills, such as Edaixi.com and Chunyuyisheng.com. (3)Collaborative production: aims at quickly forming of production capacity and optimizing allocation of resources, such as tgc.1688.com and AppleStore.

\section{Case Study Based on Business Model Canvas \\ 3.1 Analytical Framework}

In order to explore the internal characteristics of the sharing economic model more clearly, this paper takes nine essential dimensions as the analytical framework based on the Business Model Canvas which includes customer segments, value propositions, channels, customer relationships, revenue streams, key resources, key activities, key partnerships and cost structure [9] to do comparative analysis on typical enterprises of different types of business models. Among them, customer segments refer to a company should identify who is customer and how to meet customer's demand. Value propositions means the way of providing values of products and services to meet the needs of its customers, and can be subdivided into three categories: addition, that is, add value to customers or create new value; subtraction, that is, reduce costs or lower the risks for customers; multiplication, which help customers increase cooperative capacity ("value integration") and innovation ability [10]. Channels can be described simply as how product information is delivered to consumers. Customer relationships can be described as how companies gain customers, maintain customers and induce customers to consume. The revenue streams can simply be seen as the main business source. Key resources refer to tangible and intangible resources with core competence in enterprise competition. Key activities are the most important activities for the organization to achieve operational success. A key partner is a key stakeholder based on a number of factors. Cost structure refers to the expense cost required by enterprises to carry out production and business activities. We select several cases form different industries: Uber、Didi and Mobike; xiaozhu.com; chunyuyisheng.com; daojia.com; yikexue.com; Shenyang and Machine Tool. Through search the open resources and browsing the web information, we extract qualitative data about the nine elements of business model based on different cases, and comparative analysis among different types of sharing economy has been done.

\subsection{Analysis Results}

Through analysis on nine key factors of above cases, it was found that value propositions provided to customers are mainly reflected in: (i) Subtraction: to reduce costs or lower the risks for customers; (ii) Addition, that is, creating new value for customers by provision of idle resources; delivering value by changing resource access method of customers (resource's user). But significant value integration features have been not yet found based on the above cases.

As cutting-edge taxi software, Uber and Didi make easier transport services become possible. They are able to pinpoint the passenger's position with positioning system on smart phones, allowing passengers to know the nearest vehicle by touching the screen. When a user requests a ride, the driver's location, name, and other details are displayed in the app. When the vehicle is about to arrive, the system will send a text message to inform the passengers to be prepared. Using the App platform, passengers can simply estimate the cost of the ride in the application by inputting the origin and destination. Like Uber, Didi software makes passenger going out without needing to exchange any cash with the driver becomes possible, and provides riding sharing services to effectively release the idle resources of transport services. The difference between Uber and Didi is the system of payment. In Uber, after the passengers arrive at the destination, the system will automatically charge the credit card and electronic invoices will automatically be sent to the passenger's mailbox. But in China, users prefer to pay by mobile phone (for example through Wechat or Alipay) than by credit card and they don't like using mailbox to deal with the electronic invoices also, because it is not a timely payment system. Thus Didi provide the service of timely 
payment via Wechat. Users can pay it by mobile phone. And then passengers can also invite friends to share fares, when a friend accepts the invitation, and the system will deduct half-and-half expenses respectively from the Wechat account of the inviter and recipient. At the end of the ride, the system will also invite passengers to evaluate the service of drivers and make valuable comments. Like transport industries, the sharing models will be analyzed one by one from the perspective of business model canvas based on the above cases.

(1) Target customers. Firstly, for production and service sharing, Uber, Didi and Mobike focus on short-distance travel needs on the mass consumer market. Their target customers include the commuter, residents of a city and people with short haul traffic, and Didi or Uber's customers also include the taxi drivers. Secondly, for the types of collaborative lifestyles, the customers are mostly young peoples, especially for specific needs relied on the new technology, for example it is difficult for elderly people to take the new platform of Chunyuyisheng.com to receive medical services with lacking of technical guidance. Thirdly, for the collaborative production, customers are the two sides of the production sharing. Through the study of the target customers group, we find that Didi and Uber actually uses the network platform to integrate the consumers' demand for resources and the suppliers' idle resources for revenue generating, and realizes the effective matching. Therefore, the target customers can be defined as a resource provider that can get access to the platform and a resource provider with redundant resources. But for Mobike, there is no sharing of idle resources.

(2) Value propositions. Based on the cases studies, the value provided to users by sharing economy can be summarized into three aspects: (1)Cost saving: The platform clearly shows the demand, a large number of suppliers could mobilize large-scale idle resources to match the effective demand based on clear requirements, and thus the cost is lower to satisfy the needs. And because the demand presented on the platform is clearly visible, the supply side responds faster to the market, and the cost of service delivery is relatively lower. And Provide users with standard household services, reduce the opportunity cost for users etc.(2)Time saving: For example, reduce time cost of taxi calling, doctors may use fragmented time to answer patient questions on-line to saving time of patients, etc.(3)Creating new value: The idle assets can be vitalized to create new market and nes value[11]

(3) Channels. The company transfers product information to consumers mainly through two channels. First, the product information is delivered to the audience in virtue of official website, mobile applications and other channels, and then the product or service image is strengthened in the user's mind with word of mouth, star effect and other marketing tools. Second, the brand recognition is strengthened by using the influence of platform and cooperation with other well-known brands. The joint promotion of Uber, Lamborghini and Maserati in Singapore is a typical case.

(4) Customer relationships. Firstly, the companies gain customers by solving social problems (social pain points), for example, short transportation, on-call doctor consultation services, and house renting online etc. Secondly, customers participate in resource sharing or free information distribution through official website or mobile phones. After the transaction is completed, the platform will invite users to give feedback and continuously improve their own service levels. In addition, in the process of providing services, the company constantly improves the information and service price transparency, taking full account of the rights and interests of participants, and improving the sharing of resources to the greatest extent.

(5) Revenue streams. The revenue is mainly derived from rental charges, advertising fees and capital pool proceeds or the revenue sharing from cooperative enterprise or government subsidies.

(6) Key resources. For sharing economic platform, the author believes that key resources mainly include several categories: The brand, intellectual property and other intangible assets. Operational personnel, who are able to build platform professionals, integrate $\mathrm{O} 2 \mathrm{O}$ resources, and translate the product concept into real income. Capital resources, almost every new venture needs a large amount of capital accumulated by the investors' funds and capital pools. Service resources may include equipment like bike, technology and service providers or vendors. 
(7) Key activities. Platform development and maintenance is the key activities for the sharing economic company. And then there are equipment leasing and product design or marketing. Although Uber has been involved in life services and financial services in recent years, leasing is undoubtedly the core business of Uber.

(8) Key partnerships. The new media and internet companies are the key partnerships of the sharing economic enterprise, and of course, Venture capital firms and financial institutions are also the important cooperative partners. Uber's important partners include not only many private car owners, taxi companies, automobile manufacturers (BMW, Tesla, etc.) and Baidu and other well-known media companies. The author believes that it is important to build a platform to promote the effective matching of supply and demand of resources, but it is more important to enhance the visibility and make more participants get access to the platform with the help of media. There must be a lot of idle resources available on the platform to supply effective demand.

(9) Cost structure. The sharing economy based on the idle resources sharing or technology innovation should be light of the assets. The cost of sharing economy mainly includes staff salaries, platform maintenance fee, market costs and risk cost of capital. For Uber, in addition to the companies' conventional fixed assets investment, staff salaries and other general expenses, the platform construction and maintenance costs and advertising expenditure should account for the vast majority of the cost of such enterprises.

We found that, as a sharing economic model, information platform can effectively solve the contradiction between difficulty in providing services or resources and high rate of empty service ratio and resources of idle rate. It precisely matches a driver's supply information with a passenger's demand information in some special cases. For example, passengers have to ride in late-night in particular cases and the accurate information matching value will be more obvious. Second, idle resource sharing can meet consumer demand at a lower cost. For the owners of idle resources, the high acquisition cost and low service efficiency of houses, automobiles and other similar commodities will lead to the reduced utility and waste of vast resources. But for the demand side of such resources, the demand cannot be met because of high purchase costs, or the satisfaction degree of demand is not maximized because of a higher cost. Idle resources sharing can effectively solve this contradiction. On the one and, for resource owners, the marginal cost of shared idle resources is close to zero, which is far lower than the marginal revenue of shared assets. On the other hand, for resource demanders, their own demands can be met at a lower cost. For example, as an idle resource sharing platform of Hitching a ride in Didi, Taxi is able to share the idle carrying space to meet a passenger's need of short-distance travelling while bringing benefits to a driver. Uber also copper meet the rapid travelling needs of passengers while bringing benefits to helicopter owners by sharing carrier space of the remaining helicopters. Uber Rush reduces the opportunity cost of users by sharing the time and effort of couriers. Again, diversified income distribution channels improve job flexibility. That realise the reusing of idle resources more easily.

Another important reason for great concern for sharing economy is that revenue streams are broadened through tangible physical or intangible resources in the context of the economic downturn, which brings more revenue to the resource provider. The idle resource sharing platform breaks the traditional rigid employment relationship. On the network platform, people will no longer depend on an entity organization and provide labour to create value. At the same time, positions on the demand-based platforms are also much more diversified, and labour employment has become more flexible.

\section{Conclusion}

On the one hand, the sharing economy makes resource owners have the opportunity to use idle resources or fragmented time to increase revenue; on the other hand, it reduces the cost of living while ensuring quality of life for resource demanders. Therefore, the future sharing economy models will become the mainstream of modern service industries. In addition, the development of mobile Internet and the popularity of intelligent terminals are important conditions for the rapid 
development of sharing economy. In fact, the sharing behaviour in people's daily lives is ubiquitous, such as sharing a ride. But in the past, this kind of sharing behaviour was limited by time and space, so it was difficult to form a new business model [12]. The development of mobile Internet and the popularity of smart terminals make similar sharing behaviour break through the time and space constraints to generate huge market value. The sharing scope and sharing time have been extended, and mobile Internet users also contributed to the rapid development of sharing economy.

Compared with the traditional model, the sharing economy models will be more and more popular in the view of improving the efficiency and conserving the environment. With the accelerating pace of social life, sharing economy will completely change people's consumption habits. In the sharing economy model, consumers are no longer pursuing the possession of ownership, but placing more weight on the value and effectiveness of the right to use. In the future, sharing economy gives full play to its advantages in terms of saving time and opportunity costs, as well as creating resource value or changing the value delivery, and will achieve unlimited value integration through collaboration. Therefore, more and more enterprises will provide services to customers through value integration.

\section{References}

[1]Zhang Xinhong, Gao Taishang, Yu Fengxia,etc, Research group on sharing economy development report, China sharing economy development report: status, problems and trends[J]. E-Government, 2016 (4):11-27.

[2]Rachel Botsman, What' $\mathrm{s}$ mine is yours: The Rise of Collaborative Consumption[J]. American: Tantor Media, 2010:83-110.

[3]He Yunyun, Disputes arising from special car service under the theory of sharing economy [J]. Business. 2015(6):256.

[4]Weitzman, M.L., Increasing Returns and the Foundations of Unemployment Theory[J]. Economic Journal. 1982, 92(368):787-804.

[5]Weitzman, M.L. Some Macroeconomic Implications of Alternative Compensation Systems[J]. Economic Journal. 1983,93(372):763-783.

[6]Weitzman, M.L. The Share Economy: Conquering Stagflation[M]. Boston: Harvard University Press. 1984

[7]Weitzman, M.L. The simple macroeconomics of profit sharing[J]. American Economic Review. 1985,75(2):937-953.

[8]Weitzman, M.L. The Share Economy: Conquering Stagflation[J]. Rand Journal of Economics. 1986,16(4):581.

[9]Osterwalder A., Pigneur Y., Business Model Generation[J]. African Journal of Business Management, 2010, 29(6):2549-2557.

[10]Liu Bo. Impact of E-business on the traditional business model[J].Modern Communication 2016(13):94-95.

[11]Yan Jingyu. Uber enlightenment and leading the development of global sharing economy[J]. Market Modernization, 2015,(19):13-17.

[12]Dong Chenghui., Sharing economy-theory and reality[J]. Journal of Guangdong University of Finance \& Economics, 2016 (5):4-15. 